nate variation is permitted. Thus, the selective premium upon variation 99 being no greater than that upon 98,98 would have as good a chance of leaving offspring (which wculd inherit and transmit this variation) as would 99 : similarly, 97 would have as good a chance as 98 , and so on. Now there is thus a much greater chance of variations being perpetuated at or below 99 , than at or above 100 ; for at 100 the hard line of Selection (or Economy) is fixed, while there is no corresponding line below roo. The consequence of free intercrossing would therefore be to reduce the average from 100 to 99 . Simultaneously, however, with this reducing process, other variations would be surviving below 99 , in greater numbers than above 99 ; consequently the average would next become reduced to 98 . There would thus be "two operations going on side by side-the one ever destroying the symmetry of distribution" round the average, "and the other ever tending to restore it." It is evident, however, that the more the average is reduced by this process of indiscriminate variation, the less chance there remains for its further reduction. When, for instance, it falls to 9o, there are (numerically, though not actually, because of Inheritance) 89 to 9 in favour of climinution; but, when it falls to 80 , there are only 79 to 19 in such favour. Thus (theoretically) the average would continue to diminish at a slower and slower rate, until it comes to 5o, where, the chances in favour of increase and of diminution being equal, it would remain stationary.

Having thus, for the sake of clearness, considered this principle apart, let us row observe the effect of superadding to it the influence of the Econony of Growth-a principle with which its action must always be associated. Briefly, as this influence would be that of continually favouring the variations on the side of diminution, the effect of its presence would be that of continuously preventing the average from becoming fixed at 50,40 , 3o, \&c. In other words, the "hard line of Selection," which was originally placed at 100 , would now become progressively lowered through $90,80,70, \& c$. ; always allowing indiscriminate variation below the barrier, but never above it.

It will be understood that by "cessation of selection from changed conditions of life" I mean a change of any kind which renders the affected organ superfluous. Take, for example, the exact converse of Mr. George Darwin's illustration, by supposing a herd of cattle to migrate from a small tract of poor pasture to a large tract of rich. Segregation would ensue, the law of battle would become less severe, while variation would be pro. moted in a cumulative manner by the increase of food. The young males with shorter horns would thus have as good a chance of leaving progeny as "their longer-horned brothers," and the average length would gradually diminish as in the other case. Of course, as the predisposing cause of impoverished nutrition would now be absent, the reducing process would take place at a slower rate. Moreover, it is to be remarked that this principle differs in an important particular from that enunciated by $\mathrm{Mr}$. Darwin, in that it could never reduce an organ much below the point at which the Economy of Growth (together wi h Disuse) ceases to act. For, returning to our numerical illustration, suppose this point to be 6 , the average would eventually become fixed at 3 .

That the principle thus explained has a real existence we may safely conclude, theoretical considerations apart, from the analogy afforded by our donsestic races; for nothing is more certain to breeders than the fact that neglect causes degereration, even though the strain be kept isolated. It will be observed that, if this principle has a real existence, it is of considerable importance, theoretically, since it must act, to a greater or less extent, in all cases where Disuse and the Economy of Growth are in operation; and although in the initial stages of reduction, when the purchase, so to speak, of the last-named r rinciple is great, its influence would be eomparatively trivial, this influence would be more and more felt the smaller the organ became-i.e., the nearer the point at which the Economy of Growth ceases to act. The Cessation of Selection should therefore be regarded as a reducing cause, which co-operates with other reducing causes in all cases, and which is of special importance as an accelerating agent when the influence of the latter becomes feeble.

Georgu J. Romanes

\section{Lakes with two Outfalls}

ON June 22, 1863 , the late Captain Speke published his map, giving (on native authority) four outlets from Lake Victoria Nyanza, converging to one valley or water-flow-the Nile.
On June 27 and on July 201 wrote to the Athenoum :- "I think that this native information will prove to be erroneous;" that I thought "that no lake can have more than one outlet ;" and $I$ added, "May $I$ lay the question as to the matter of fact before the readers of the Athenceum?" In reply, the Black Loch in Dumfriesshire was stated to have two outlets to two distinct valleys or water-flows-one to the Nith, the other to the Ayr. The Loch, however, has but one outlet, and that artificial. The water-parting has been cut through by man--a mill-lead made to Lord Bute's Borland mill, and the one outlet is an iron sluice in a stone dam. All this is beautifully shown in Sir Henry James's admirable 25-inch Ordnance Maps.

Dr. Bryce ("Geology of Arrau," 3rd edition, p. 3) says that Loch-an-Davie has two outlets to two different valleys. It has, however, but one outlet, to the south-to Glen Iorsa, as I stated in the Athenceum, July 22, 1865 . The new inch Ordnance Map of Arran gives one outlet, but unfortunately to the north, instead of to the south. I will not refer to my letter on the two outlets to two valleys from the Norwegian Lesjeskaugen Lake, which you did me the honour to publish last September, and with which Prof. Stanley Jevons agreed. But I quote the above cases to show that even the highest authorities make mistakes as regards lakes and their outlets. I cannot, however, suppose any mistake in Prof. Bell's account of the two outlets to two valleys from Shoal I ake, published in NATURE, vol. ix. p. 363, by Prof. Dawson. I would then, in deference to these authorities, modify my dictum by saying, that if by a rare possibility a lake may be found to exist on a water-parting having at opposite ends two outlets to two different valleys, I should still doubt the possibility of a lake at its one lower end having a multiplicity of outlets converging to one valley or water-flow, as in the case of the Victoria Nyanza. And this owing to the extreme insprobability that the erosion at each outlet should continue at precisely the same rate.

The outlet of every lake in the wide, wide world is always being lowered from erosion, as are valleys themselves. Valleys exist only in the dissolution of hills. They are mere water-flow: They are the perpetually changing effects of atmospheric disintegration, and the erosion of rain and rivers, and consequently every water-parting is a valley-parting.

Alresford, March 14

George Greanwood

\section{A Beech pierced by a Thorn Plani}

On the road from this to Belfast there is a thorn hedge with beech trees at intervals, and thorn plants have grown right through the mildie of the trunks of two of the beeches. I do not know whether this is sufficiently uncommon to be worth mentioning in NATURE.

Old Forge, Dunmurry, co. Antrim

\section{KINETIC THEORY OF THE DISSIPATION OF}

\section{ENERGY}

IN abstract dynamics an instantaneous reversal of the motion of every moving particle of a system causes the system to move backwards, each particle of it along its old path, and at the same speed as before when again in the same position-that is to say, in mathematical language, any solution remains a solution $w h \leqslant n t$ is changed into $-t$. In physical dynamics, this simple and perfect reversibility fails on account of forces depending on friction of solids; imperfect fluidity of fluids ; imperfect elasticity of solids; inf qualities of temperature and consequent conduction of heat produced by stresses in solids and fluids; imperfect magnetic retentiveness; residual electric polarisation of dielectrics; generation of heat by electric currents induced by motion; diffusion of fluids, solution of solids in fluids, and other chemical changes; and absorption of radiant heat and light. Consideration of these agencies in connection with the all-pervading law of the conservation of energy proved for them by Joule, led me twenty-three years ago to the theory of the dissipation of energy, which I communicated first to the Royal Society of Edinburgh in 1852 , in a paper entitled 
"On a Universal Tendency in Nature to the Dissipation of Mechanical Energy,

The essence of Joule's discovery is the subjection of physical phenomena to dynamical law. If, then, the motion of every particle of matter in the universe were precisely reversed at any instant, the course of nature would be simply reversed for ever after. The bursting bubble of foam at the foot of a waterfall would reunite and descend into the water : the thermal motions would reconcentrate their energy and throw the mass up the fall in drops reforming into a close column of ascending water. Heat which had been generated by the friction of solids and dissipated by conduction, and radiation with absorption, would come again to the place of contact and throw the moving body back against the force to which it had previously yielded. Boulders would recover from the mud the materials required to rebuild them into their previous jagged forms, and would become reunited to the mountain peak from which they had formerly broken away. And if also the materialistic bypothesis of life were true, living creatures would grow backwards, with conscious knowledge of the future, but no memory of the past, and would become again unborn. But the real phenomena of life infinitely transcend human science, and speculation regarding consequences of their imagined reversal is utterly unprofitable. Far otherwise, however, is it in respect to the reversal of the motions of matter uninfluenced by life, a very elementary consideration of which leads to the full explanation of the theory of dissipation of energy.

To take one of the simplest cases of the dissipation of energy, the conduction of heat through a solid--consider a bar of metal warmer at one end than the other and left to itself. To avoid all needless complication, of taking loss or gain of heat into account, imagine the bar to be varnished with a substance impermeable to heat. For the sake of definiteness, imagine the bar to be first given with one half of it at one uniform temperature, and the other half of it at another uniform temperature. Instantly a diffusing of heat commences, and the distribution of temperature becomes continuously less and less unequal, tending to perfect uniformity, but never in any finite time attaining perfectly to this ultimate condition. This process of diffusion could be perfectly prevented by an army of Maxwell's "intelligent demons"* stationed at the surface, or interface as we may call it with Prof. James Thomson, separating the hot from the cold part of the bar. To see precisely how this is to be done, consider rather a gas than a solid, because we have much knowledge regarding the molecular motions of a gas, and little or no knowledge of the molecular motions of a solid. Take a jar with the lower half occupied by cold air or gas, and the upper half occupied with air or gas of the same kind, but at a higher temperature, and let the mouth of the jar be closed by an air-tight lid. If the containing vessel were perfectly impermeable to heat, the diffusion of heat would follow the same law in the gas as in the solid, though in the gas the diffusion of heat takes place chiefly by the diffusion of molecules, each taking its energy with it, and only to a small proportion of its whole amount by the interchange of energy between molecule and molecule; whereas in the solid there is little or no diffusion of substance, and the diffusion of heat takes place entirely, or almost entirely, through the comrnunication of energy from one molecule to another. Fourier's exquisite mathematical analysis expresses perfectly the statistics of the process of diffusion in each case, whether it be "conduction of heat," as Fourier and his followers have called it, or the diffusion of substance in fluid masses (gaseous or liquid) which Fick showed to be subject to Fourier's formulae. Now, suppose the weapon of the ideal army to be a club, * The definition of a "demon." according to the use of this word by Maxwell, is an intelligent being endowed with free will, and fine enough tac tile and perceptive organisation to give him the faculty of observing and influencing individual molecules of matter or, as it were, a molecular cricket-bat; and suppose for convenience the mass of each demon with his weapon to be several times greater than that of a molecule. Every time he strikes a molecule he is to send it away with the same energy as it had immediately before. Each demon is to keep as nearly as possible to a certain station, making only such excursions from it as the execution of his orders requires. He is to experience no forces except such as result from collisions with molecules, and mutual forces between parts of his own mass, including his weapon: thus his voluntary movements cannot influence the position of his centre of gravity, otherwise than by producing collision with molecules.

The whole interface between hot and cold is to be divided into small areas, each allotted to a single demon. The duty of each demon is to guard his allotment, turning molecules back or allowing them to pass through from either side, according to certain definite orders. First, let the orders be to allow no molecules to pass from either side. The effect will be the same as if the interface were stopped by a barrier imperneable to matter and to heat. The pressure of the gas being, by hypothesis, equal in the hot and cold parts, the resultant momentum taken by each demon from any considerable number of molecules will be zero; and therefore he may so time his strokes that he shall never move to any considerable distance from his station. Now, instead of stopping and turning all the molecules from crossing his allotted area, let each demon permit a hundred molecules chosen arbitrarily to cross it from the hot side ; and the same number of molecules, chosen so as to have the same entire amount of energy and the same resultant momentum, to cross the other way from the cold side. Let this be done over and over again within certain small equal consecutive intervals of time, with care that if the specified balance of energy and momentum is not exactly tulfilled in respect to each successive hundred molecules crossing each way, the error will be carried forward, and as nearly as may be corrected, in respect to the next hundred. Thus, a certain perfectiy regular diffusion of the gas both ways across the interface goes on, while the original different temperatures on the two sides of the interface are maintained without change.

Suppose, now, that in the original condition the temps. rature and pressure of the gas are each equal throughout the vessel, and let it be required to disequalise the temperature but to leave the pressure the same in any two portions $A$ and $B$ of the whole space. Siation the army on the interface as previously described. Let the orders now be that each demon is to stop all molectiles from crossing his area in either direction except roo coming from $A$, arbitrarily chosen to be let pass into $B$, and a greater number, having among them less energy but equal momentum, to cross from $B$ to $A$. Let this be repeated over and over again. The temperature in $A$ will be cortinually diminished and the number of molecules in it continualiy increased, until there are not in $B$ enough of molecules with smali enough velocities to fultil the condition with reference to permission to pass from $B$ to $A$. If after that no molecule be allowed to pass the interface in either direction, the final condition will be very great condensation and very low temperature in $A$; rarefaction and very high temperature in $B$; and equal temperature in $A$ and $B$. The process of disequalisation of temperature and density might be stopped at any time by changing the orders to those previously specified (2), and so permitting a certain degree of diffusion each way across the interface while maintaining a fertain uniform difference of temperatures with equality of pressure on the iwo sides.

If no selective influence, such as that of the ideal "demon," guides individual molecules, the average result of their free motions and collisions must be to equalise the distribution of energy among 
them in the gross; and after a sufficiently long time from the supposed initial arrangement the difference of energy in any two equal volumes, each containing a very great number of molecules, must bear a very small proportion to the whole amount in either; or, more strictly speaking, the probability of the difference of energy exceeding any stated finite proportion of the whole energy in either is very small. Suppose now the temperature to have become thus very approximately equalised at a certain time from the beginning, and let the motion of every particle become instantaneously reversed. Each molecule will retrace its former path, and at the end of a second interval of time, equal to the former, every molecule will be in the same position, and moving with the same velocity, as at the beginning; so that the given initial unequal distribution of temperature will again be found, with only the difference that each particle is moving in the direction reverse to that of its initial motion. This difference will not prevent an instantaneous subsequent commencement of equalisation, which, with entirely different paths for the individual molecules, will go on in the average according to the same law as that which took place immediately afier the system was first left to itself.

By merely looking on crowds of molecules, and reckoning their energy in the gross, we could not discover that in the very special case we have just considered the progress was towards a succession of states in which the distribution of energy deviates more and more from uniformity up to a certain time. The number of molecules being finite, it is clear that small finite deviations from absolute precision in the reversal we have supposed would not obyiate the resulting disequalisation of the distribution of energy. But the greater the number of molecules, the shorter will be the time during which the disequalising will continue ; and it is only when we regard the number of molecules as practically infinite that we can regard spontaneous disequalisation as practically impossible. And, in point of fact, if any finite number of perfectly elastic molecules, however great, be given in motion in the interior of a perfectly rigid vessel, and be left for a sufficiently long time undisturbed except by mutual impacts and collicions against the sides of the containing vessel, it must happen over and over again that (for example) something more than nine-tentbs of the whole energy shall be in one half of the vessel, and less than one-tenth of the whole energy in the other half. But if the number of molecules be very great, this will happen enormously less frequently than that something more than 6-Ioths shall be in one half, and something less than 4-roths in the other. Taking as unit of time the average interval of free motion between consecutive collisions, it is easily seen that the probability of there being something more than any stated percentage of excess above the half of the energy in one halt of the vessel during the unit of time, from a stated instant, is smaller the greater the dimensions of the vessel and the greater the stated percentage. It is a strange but neve:theless a true conception of the old well-known law of the conduction of heat to say that it is very improbable that in the course of 1,000 years one half the bar of iron shall of itself become warmer by a degree than the other half; and that the probability of this happening before $I, 000,000$ years pass is 1,000 tines as great as that it will happen in the course of $x, 000$ years, and that it certainly will happen in the course of some very long time. But let it be remembered that we have supposed the bar to be covered with an impermeable varnish. Do away with this impossible ideal, and believe the number of molecules in the universe to be infinite; then we may say one half of the bar will never become warmer than the other, except by the agency of external sources of heat or cold. This one instance suffices to explain the philosophy of the foundation on which the theory of the dissipation of energy rests.
Take however another case in which the probability may be readily calculated. Let a hermetically-sealed glass jar of air contain 2,000,000,000,000 molecules of oxygen, and $8,000,000,000,000$ molecules of nitrogen. If examined any time in the infinitely distant future, what is the number of chances against one that all the molecules of oxygen and none of nitrogen shall be found in one stated part of the vessel equal in volume to $1-5$ th of the whole? The number expressing the answer in the Arabic notation has about $2,173,220,000,000$ of places of whole numbers. On the other hand the chance against there being exactly 2 -I oths of the whole number of particles of nitrogen, and at the same time exactly 2 -Ioths of the whole number of particles of oxygen in the first specified part of the vessel is only $4021 \times 10^{9}$ to 1 .

\section{[Appendix:-Calculation of Probability respecting Diffu- sion of Gases.]}

For simplicity I suppose the sphere of action of each molecule to be infinitely small in comparison with its average distance from its nearest neighbour: thus, the sum of the volumes of the spheres of action of all the molecules will be infinitely small in proportion to the whole volume of tie containing vessel. For brevity, space external to the sphere of action of every molecule will be called free space : and a molecule will be said to be in free space at any time when its sphere of action is wholly in free space; that is to say, when its sphere of action does not overlap the sphere of action of any other molecule. Let $A, B$ denote any two particular portions of the whole containing vessel, and let $a, b$ be the volumes of those portions. The chance that at any instant one individual molecule of whichever gas shall be in $A$ is $\frac{a}{a+b}$, however many or few other molecules there may be in $A$ at the same time; because its chances of being in any specified portions of free space are proportional to their volumes; and, according to our supposition, even if all the other molecules were in $A$, the volume of free space in it would not be sensibly diminished by their presence. The chance that of $n$ molecules in the whole space there shall be $i$ stated individuals in $A$, and that the other $n-i$ molecules shall be at the same time in $B$, is

$$
\left(\frac{a}{a+b}\right)^{i}\left(\frac{b}{a+b}\right)^{n-i} \text {, or } \frac{a^{i} b^{n-i}}{(a+b)^{n}}
$$

Hence the probability of the number of molecules in $A$ being exactly $i$, and in $B$ exactly $n-i$, irrespectively of individuals, is a fraction having for denominator $(a+b)^{n}$, and for numerator the term involving $a^{i} b^{n-i}$ in the expansion of this binomial; that is to say it is -

$$
\frac{n(n-1) \cdots(n-i+x)}{\mathrm{I} \cdot 2 \cdots\left(\frac{a}{a+b}\right)^{i}}\left(\frac{b}{a+b}\right)^{n-i}
$$

If we call this $T_{i}$ we have

$$
T_{i+\mathrm{x}}=\frac{n-i}{i+\mathrm{x}} \frac{a}{b} T_{i+\mathrm{x}}
$$

Hence $T_{i}$ is the greatest term if $i$ is the smallest integer which makes

$$
\frac{n-i}{i}+\frac{i}{1}<\frac{b}{a}
$$

this is to say, if $i$ is the smallest integer which exceeds

$$
n-\frac{a}{a+b}-\frac{b}{a+b}
$$

Hence if $a$ and $b$ are commensurable the greatest term is that for which

$$
i=i \frac{a}{a+b}
$$

To apply these results to the cases considered in the preceding article, put in the first place

$$
n=2 \times 10^{12}
$$

this being the number of particles of oxygen; and let $i=n$. Thus, for the probability that all the particles of oxygen shall be in $A$, we find

$$
\left(\frac{a}{a+b}\right)^{8 \times 10^{12}}
$$


Similarly, for the probability that all the particles of nitrogen are in the space $B$, we find

$$
\left(\frac{b}{a+b}\right)^{2} \times 10^{12}
$$

Hence the probability that all the oxygen is in $A$ and all the nitrogen in $B$ is

$$
\left(\frac{a}{a+b}\right)^{2} \times 10^{12} \times\left(\begin{array}{c}
b \\
a \times b
\end{array}\right)^{8 \times 10^{12}}
$$

Now by hypothesis

and therefore

$$
\frac{a}{a+b}=\frac{2}{10}
$$

$$
\frac{b}{a+b}=\frac{8}{10}
$$

herce the required probability is

$$
\frac{2^{26 \times 10^{12}}}{10^{10^{13}}}
$$

Call this $\frac{\mathrm{I}}{\bar{V}}$, and let log denote common logarithm. We bave $\log N=10^{13}-26 \times 10^{12} \times \log .2=(10-26 \log .2) \times 10^{12}=$ $2173220 \times 10^{6}$. This is equivalent to the result stated in the text above. The logarithm of so great a number, unless given to more than thirteen significant places, cannot indicate more than the number of places of whole numbers in the answer to the proposed question, expressed according to the Arabic notation.

The calculation of $T_{i}$ when $i$ and $n-i$ are very large numbers is practicable by Stirling's Theorem, according to which we have approximately

$$
\begin{aligned}
& \text { and therefore } \\
& \frac{n(n-1) \cdots(n-i+1)}{\mathrm{I} \cdot 2 \cdots \cdot}=\frac{n^{n}+\frac{1}{3}}{\sqrt{2 \pi} i\left(i+\frac{1}{2}\right)(n-i)^{n}}
\end{aligned}
$$

Hence for the case

$$
i=n \frac{a}{a+b}
$$

which, according to the preceding formulæ, gives $T_{i}$ its greatest value, we have

where

$$
T_{i}=\frac{i}{\sqrt{2 \pi n e f}}
$$

$$
e=\frac{a}{a+b} \text { and } f=\frac{b}{a+b}
$$

Thus, for example, let $n=2 \times 10^{12}$;

we have

$$
e=2, f=\cdot 8
$$

$$
T_{i}=\frac{\mathrm{I}}{800000 \sqrt{\pi}}=\frac{\mathrm{I}}{\mathrm{I} 4 \mathrm{I} 8000}
$$

This expresses the chance of there being $4 \times 10^{11}$ molecules of oxygen in $A$, and $16 \times 10^{11}$ in $B$. Just half this fraction expresses the probability that the molecules of nitrogen are distributed in exactly the same proportion between $A$ and $B$, because the number of molecules of nitrogen is four times greater than of oxygen.

If $n$ denote the molecules of one gas, and $n^{\prime}$ that of the molecules of another, the probability that each shall be distributed between $A$ and $B$ in the exact proportion of the volume is

$$
\frac{1}{2 \pi e f \sqrt{n n^{\prime}}}
$$

The value $f(x$ the supposed case of oxrgen and nitrogen is

$$
\frac{1}{2 \pi \times 16 \times 4 \times 10^{12}}=\frac{1}{4021 \times 10^{9}}
$$

which is the result stated at the conclusion of the lext above.

$$
\text { WILLIAM THOMSON }
$$

\section{LIVINGSTONE'S WORK IN AFRICA}

$T$ HE daily papers have published some extracts from a letter written from Lake Bangweolo, of the late Dr. Livingstone to Mr. H. M. Stanley, which have been kindly furnished by the enterprising proprietor of the New York Herald; we reproduce here so much of the letter as bears on the geographical work done by Livingstone.

"The Chambezi was crossed long ago by the Portuguese, who have thus the merit of its discovery in modern times. The similarity of names led to its being put down in maps as 'Zambesi' (eastern branch) and I rather stupidly took the error as having some sort of authority. Hence my first crossing it was as fruitless as that of the Portuguese. It took me twenty-two months to eliminate this error.

"The Cazembe who was lately killed was the first who gave me a hint that Chambezi was one of a chain of rivers and lakes which probably forms the Nile; but he did it in rather a bantering style that led me to go back to the head waters again and see that it was not the mere 'chaff' of a mighty potentate. There is Omar Island in the middle of Bangueldo, with $183^{\circ}$ of sea horizon around. The natives, slowly drawing the hand around, said-'That is Chambezi flowing round all this space and forming Bangweolo before it winds round that headland and changes its name to Luapula.' That was the moment of discovery and not the mere crossing of a small river.

"The late Cazembe I found sensible and friendly. His empire has succumbed before a very small force of Arab slaves and Banyamwezi. Pereira, the first Portuguese who visited the Cazembe eighty years ago, said that he had 30,000 trained soldiers, sacrificed twenty human victims every day, and that the streets of his capital were watered daily. I thought that my late friend had $30,0(0)$, diminished by two oo's, and sacrificed five or six pots of pombe daily; but this may have been only a court scandal - the streets of his village were not made. So I was reminded of the famous couplet about the Scotch roads :-

" "If you had seen these roads before they were made,

You would lift up your hands and bless General Wade.'

"I have been the unfortunate means of demolishing two empires in Portuguese geography-the Cazembes and that of the Emperor Monomotapa:' I found the last about ten days above Tette. He had too few men to make the show Cazembe did, but I learnt from some decent motherly-looking women attached to his Court Zembere (?) that he had 100 wives. I have wondered ever since and have been nearly dumfoundered with the idea of what a nuisance a man with 100 wives in England would be. It is awful to contemplate, and might be chosen as a theme for a Young Men's Debating Society. I wish someone would visit Mtesa, or Uganda, without Bombay as an interpreter. He (Bombay) is by no means a sound author. The King of Dahomey suffered eclipse after a common-sense visit, and we seldom hear any more of his atrocities. The mightiest African potentate and the most dreadful cruelties told of Africans owe a vast deal to the teller.

"You and I passed the islet Kasenge, where African mothers were said to sell their infants for a loin-cloth each. This story was made to fit into another nice little story of 'a mother bear' that refused to leave her young. A child that cuts its upper front teeth before the under is dreaded as unlucky and likely to bring death into the family. It is called an Arab child, and the first Arab who passes is asked to take it. I never saw a case, nor have the Arabs I. have asked seen one either, but they have heard of its occurrence. The Kasenge story is, therefore, exactly like that of the Frenchman who asserted that the English were so fond of hanging themselves in November you might see them swinging on trees along the road. He may have seen one; I never did. English and American mothers have been guilty of deserting infants; but who would turn up the whites of his eyes and say, as our mothers at Kasenge did, these people are no better than, or not so good as, she-bears?

"This lake, so far as I have seen it, is surrounded by 